Atmos. Chem. Phys., 17, 10383-10393, 2017

https://doi.org/10.5194/acp-17-10383-2017

(c) Author(s) 2017. This work is distributed under

the Creative Commons Attribution 3.0 License.

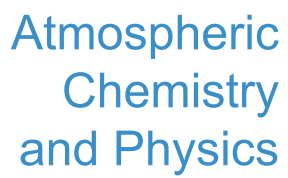

(c) (P)

\title{
Tracing changes in atmospheric moisture supply to the drying Southwest China
}

\author{
Chi Zhang ${ }^{1}$, Qiuhong Tang ${ }^{1,5}$, Deliang Chen ${ }^{2}$, Laifang $\mathrm{Li}^{3}$, Xingcai Liu ${ }^{1}$, and Huijuan Cui ${ }^{4}$ \\ ${ }^{1}$ Key Laboratory of Water Cycle and Related Land Surface Processes, Institute of Geographic Sciences and Natural \\ Resources Research, Chinese Academy of Sciences, Beijing, China \\ ${ }^{2}$ Regional Climate Group, Department of Earth Sciences, University of Gothenburg, Gothenburg, Sweden \\ ${ }^{3}$ Earth and Ocean Sciences, Nicholas School of the Environment, Duke University, Durham, USA \\ ${ }^{4}$ Key Laboratory of Land Surface Pattern and Simulation, Institute of Geographic Sciences and Natural Resources \\ Research, Chinese Academy of Sciences, Beijing, China \\ ${ }^{5}$ University of Chinese Academy of Sciences, Beijing, China \\ Correspondence to: Qiuhong Tang (tangqh@igsnrr.ac.cn)
}

Received: 15 February 2017 - Discussion started: 17 March 2017

Revised: 10 August 2017 - Accepted: 10 August 2017 - Published: 5 September 2017

\begin{abstract}
Precipitation over Southwest China (SWC) significantly decreased during 1979-2013. The months from July to September (JAS) contributed the most to the decrease in precipitation. By tracing moisture sources of JAS precipitation over the SWC region, it is found that most moisture originates in regions from the northern Indian Ocean to SWC and from South China Sea to SWC. The major moisture contributing area is divided into an extended west region, SWC, and an extended east region. The extended west region is mainly influenced by the South Asian summer monsoon (SASM) and the westerlies, while the extended east region is mainly influenced by the East Asian summer monsoon (EASM). The extended west, SWC, and extended east regions contribute $48.2,15.5$, and $24.5 \%$ of the moisture for the SWC precipitation, respectively. Moisture supply from the extended west region decreased at a rate of $-7.9 \mathrm{~mm} \mathrm{month}^{-1}$ decade $^{-1}$, whereas that from the extended east increased at a rate of $1.4 \mathrm{~mm}$ month $^{-1}$ decade $^{-1}$, resulting in an overall decrease in moisture supply. Further analysis reveals that the decline of JAS precipitation is mainly caused by change in the seasonal-mean component rather than the transient component of the moisture transport over the SWC region. In addition, the dynamic processes (i.e., changes in wind) rather than the thermodynamic processes (i.e., changes in specific humidity) are dominant in affecting the seasonal-mean moisture transport. A prevailing easterly anomaly of moisture transport that weakened mois-
\end{abstract}

ture supply from the Indian Ocean is to a large extent responsible for the precipitation decrease over the SWC region.

\section{Introduction}

Frequent and severe droughts have hit Southwest China (SWC) over the last decades, with record-breaking events in the summer of 2006 and 2011, causing great losses to society. The intensified drought is characterized by the persistent deficit of precipitation (Wang et al., 2015b), and has attracted much attention (e.g., Barriopedro et al., 2012; Feng et al., 2014; Wang et al., 2015b; Tan et al., 2016; He et al., 2016; X. Zhang et al., 2017).

Many studies have analyzed the meteorological conditions that caused the extremely low precipitation for individual drought cases (e.g., Li et al., 2011; Lu et al., 2011; Yang et al., 2012). Taking the drought of summer 2006 as an example, a stronger western Pacific subtropical high (WPSH) was found to lie anomalously northward and westward ( $\mathrm{Li}$ et al., 2011). Under the direct control of WPSH, descending motion prevailed over SWC and the moisture transport from the Bay of Bengal (BOB) and South China Sea (SCS) was suppressed (Liu et al., 2009; Li et al., 2011). Further analysis revealed that the active convection over the Philippines and the weaker-than-normal heat source of the Tibetan Plateau drove the strengthened WPSH to shift northward and west- 
ward (Li et al., 2011). Meanwhile, a weak blocking high in the Ural Mountains and a shallow East Asian trough facilitated a stronger-than-normal zonal circulation in the midlatitudes, which hindered the intrusion of cold air into SWC (Zou and Gao, 2007). In summary, the configuration of the large-scale subtropical and mid-latitude circulations was unfavorable for the warm, moist air from the south and cold, dry air from the north to converge over SWC and thus produced the severe drought.

Some recent studies have endeavored to investigate the mechanisms causing the SWC drying from a long climatological perspective. Using stalagmite record as a proxy, Tan et al. (2016) found the period of 2009-2012 was the driest ever since AD 1760 in SWC. They further attributed the drying trend to the warming of tropical ocean, which had reduced the land-sea thermal gradient and the amount of moisture transported from the BOB. In another study, the possible influence of sea surface temperature (SST) in tropical northwest Pacific (NWP) on the autumn precipitation in SWC was investigated (Wang et al., 2015a). It was found that the warm SST in NWP had likely contributed to the dry conditions in SWC in recent decades.

Although previous studies have deepened our understanding of the SWC drying through attributing individual/general drought events or long-term precipitation trend to some probable causes, few of them have analyzed the changes in the precipitation moisture sources of this region. Tracing moisture sources not only can reveal the origin of moisture for precipitation (Gustafsson et al., 2010; C. Zhang et al., 2017; James et al., 2004; Sodemann and Zubler, 2010) but also provide insight into long-term change in moisture as well as how atmospheric circulations affect precipitation in SWC. This study intends to identify changes in moisture sources of the SWC precipitation and study the relative changes in moisture transport during the last several decades to investigate the possible mechanism of the SWC drying.

\section{Data, study area, and methodology}

\subsection{Data and study area}

The reanalysis of the European Centre for Medium-Range Weather Forecasts (ECMWF) Interim (ERA-I hereafter) was used to calculate precipitable water and moisture flux (Dee et al., 2011). The ERA-I data adopted in this study are on a grid of $1.5^{\circ} \times 1.5^{\circ}$, spanning from 1979 to 2013 . The data include the $6 \mathrm{~h}$ wind and moisture content at multiple levels from 200 to $1000 \mathrm{hPa}$, and surface pressure.

Due to the existing limitation with precipitation estimates in reanalysis products (Trenberth et al., 2011; Tong et al., 2014), the ground-based $0.5^{\circ}$ gridded daily precipitation dataset from the China Meteorological Administration (CMA) was used (Zhao et al., 2014; Zhao and Zhu, 2015). The CMA dataset is based on surface observations (a) Geographic location and the elevation (m)

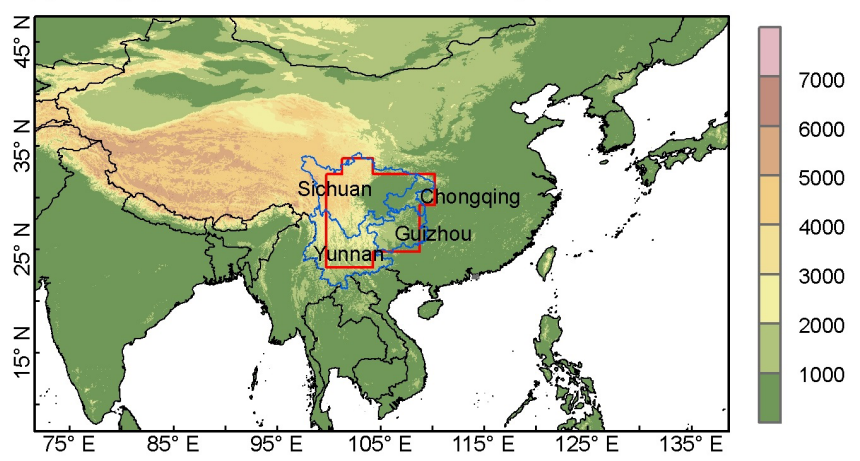

(b) Precipitation trend $\left(\mathrm{mm} \mathrm{yr}^{-2}\right)$

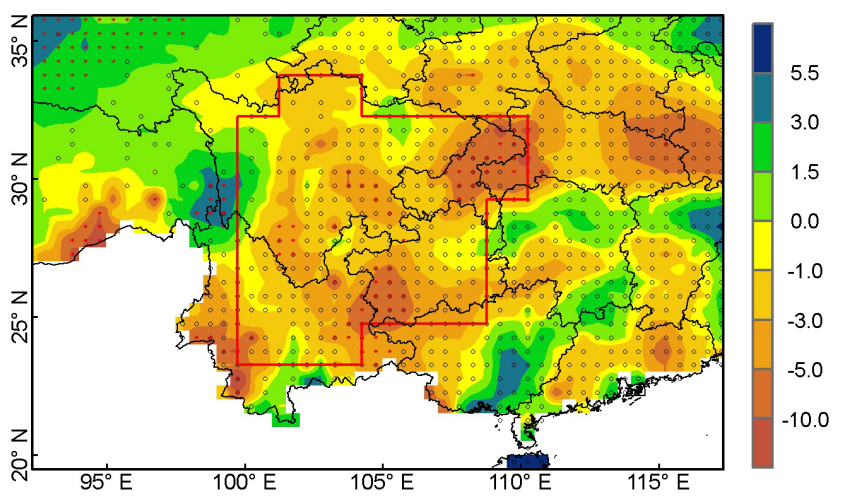

Figure 1. (a) Geographic location of SWC (red box). The blue lines delineate the major provinces/municipalities within SWC. (b) The trend of annual precipitation in SWC from 1979 to 2013 with the CMA precipitation. The circles indicate the $0.5^{\circ}$ grids with at least one rain gauge in 1979 . The red dots denote the precipitation trends with significance at the $5 \%$ level.

of $\sim 2400$ stations over China (Fig. 1a). The gauge data are quality-controlled but not homogenized. According to an estimation by Shen and Xiong (2015), the inhomogeneous stations takes up about $1.46 \%$ of all the stations. The $3 \mathrm{~h} 1^{\circ}$ gridded evaporation fields from the Community Land Model in the Global Land Data Assimilation Systems (GLDAS; Rodell et al., 2004) dataset were chosen as GLDAS outperforms other reanalysis on surface variables (Wang and Zeng, 2012; Gao et al., 2014). Over the ocean, the evaporation fields in ERA-I reanalysis were used directly, since there is no alternative estimate.

The study area of SWC mainly encompasses the three provinces of Sichuan, Yunnan, and Guizhou, as well as the municipality of Chongqing (Fig. 1a). It sits in the southeast foot of the Tibetan Plateau. In north SWC, eastern Sichuan and Chongqing form the Sichuan Basin, while in south SWC, Yunnan and Guizhou form the Yungui Plateau with an average altitude of around $2 \mathrm{~km}$. The topographic height data are provided by the Global Land One-km Base Elevation Project (GLOBE). 


\subsection{Water Accounting Model}

The Water Accounting Model (WAM) is an Eulerian model on moisture recycling, which can quantify the moisture source-sink relations between evaporation and precipitation by tracking moisture forward or backward in time (van der Ent et al., 2010; van der Ent and Savenije, 2011; Keys et al., 2012). It is quite different from those Lagrangian models such as FLEXPART and HYSPLIT which track moisture based on the particle trajectories (Stohl and James, 2004, 2005; Sodemann et al., 2008; Draxler and Hess, 1998). In this study, moisture backtracking of WAM was applied to track the moisture origins of and their changes with the SWC precipitation. The algorithm is briefly described as follows.

The input of WAM includes precipitation, evaporation, and atmospheric data (precipitable water and the vertically integrated moisture transport). The fallen precipitation in the target area was assumed to return to the air as "tagged water" in the model. The tagged water was mixed into the precipitable water with a ratio of $r$, which means only $r$ proportion of the precipitable water would finally fall into the target area. When it reverses back along the transport path, a certain amount of moisture, which is evaporated from the sources in the path, would fall into the target area. The ratio of that certain amount is also $r$. Taking the first source grid for example, it evaporates an amount of $e$ into the air at this time step. At the same time, the mixed ratio is $r$, and then only $e \times r$ would finally fall into the target area. The direct contribution from the grid at this time step is $e \times r$. The tagged water would reduce the same amount of $e \times r$ and move on to the next source grids until all the tagged water is depleted. By then, the total moisture contribution from each grid can be summed to produce a spatial distribution of moisture contributed to the precipitation in the target area.

As seen from the algorithm, WAM is a 2-D model with the "well-mixed" assumption, where the tagged water mixes into the precipitable water sufficiently and the mixed ratio is independent of height. Though the well-mixed moisture conditions are not always met, a relatively low degree of vertical mixing suffices to maintain close to well-mixed conditions for the case of moisture flux with vertically uniform wind directions (Goessling and Reick, 2013). For the case of strong directional shear of the horizontal moisture flux, a two-vertical-layer version of WAM was introduced by van der Ent et al. (2013) that solved the vertical inhomogeneities satisfactorily. The two-layer WAM is also implemented in the sensitivity analysis section as a validation to the one-layer WAM results.

The time step of WAM was set to $0.5 \mathrm{~h}$ for the $1.5^{\circ}$ grid in this study as in van der Ent et al. (2010) and van der Ent and Savenije (2011). The $6 \mathrm{~h}$ atmospheric data of precipitable water and moisture flux were linearly interpolated into the $0.5 \mathrm{~h}$ time step. For evaporation, the $1^{\circ}$ gridded GLDAS data were first interpolated into the $1.5^{\circ}$ grid over the land, and then were merged with the ocean evaporation from the ERA-I re- analysis. The merged evaporation, which was $3 \mathrm{~h}$ accumulated, was divided equally into the $0.5 \mathrm{~h}$ time step. For precipitation, in order to reflect the diurnal cycle, the daily CMA and $3 \mathrm{~h}$ ERA-I precipitation fields were merged. The CMA precipitation was firstly transformed to the same spatial resolution as ERA-I by taking the means of the $0.5^{\circ}$ grids that fell into the $1.5^{\circ}$ grid. Then both monthly CMA and ERA-I precipitations were calculated for each $1.5^{\circ}$ grid. By taking the monthly CMA value as norm, a rescaling factor $\varepsilon$ was produced for the monthly ERA-I value for each grid. All the ERA-I precipitation values $(3 \mathrm{~h})$ during a month within the grid were rescaled using the factor $\varepsilon$. Finally, the rescaled $3 \mathrm{~h}$ accumulated ERA-I precipitation was equally distributed over the $0.5 \mathrm{~h}$ time step.

When WAM is applied at a monthly scale, a large amount of tagged water may be left in the air after 1 month of tracking rather than allocated to the surface sources. Many studies have shown that the average residence time of water vapor in the atmosphere is about 10 days (Trenberth, 1998; Numaguti, 1999; Trenberth, 1999). The ratio of tagged water to residence time is $e$-folding based. There would be $1 / e$ (i.e., $36.8 \%$ ) of the original water vapor left in the air after about 10 days. The backtracking in this study is set to continue to run another 30 days with no input of precipitation. This setting would make most (more than $95 \%$ ) of the monthly precipitation moisture be allocated to the surface sources. Taking July precipitation moisture tracking over the SWC region as an example, the tracked moisture accounts for $65.1 \%$ of precipitation on average from 1979 to 2013 if the tracked period is in July only, while it accounts for $97.4 \%$ if the tracked period covers June and July.

\subsection{Decomposing moisture transport}

To further understand the change of moisture transport in association with the change of moisture origin, the monthly vertically integrated moisture flux was decomposed into a stationary component and a transient component (Eq. 1; L. Li et al., 2013).

$$
\overline{\boldsymbol{Q}}=\underbrace{\frac{1}{g} \int_{P_{\mathrm{t}}}^{P_{\mathrm{s}}} \bar{q} \overline{\boldsymbol{V}} \mathrm{d} p}_{\text {Stationary }}+\underbrace{\frac{1}{g} \int_{P_{\mathrm{t}}}^{P_{\mathrm{s}}} \overline{q^{\prime} \boldsymbol{V}^{\prime}} \mathrm{d} p}_{\text {Transient }},
$$

where $Q$ is the vertically integrated moisture flux, $g$ is the acceleration of gravity, $q$ is the specific humidity, $V$ is the horizontal wind vector, $P_{\mathrm{s}}$ is the surface pressure, and $P_{\mathrm{t}}$ is the pressure at the top of the troposphere. The bars denote the monthly mean of variables, which is calculated using the average of 6-hourly values in each month. The apostrophes denote the anomalies of 6-hourly values to their monthly mean. The stationary component is the monthly mean moisture transported by the monthly mean wind, while the tran- 
(a) Annual precipitation series over SWC

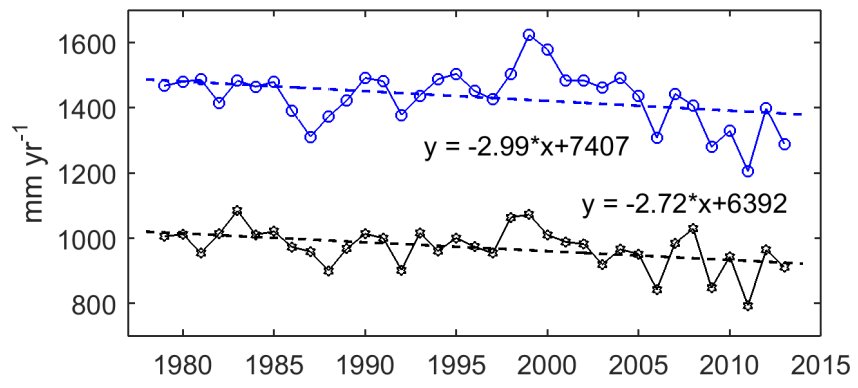

(b) JAS precipitation series over SWC

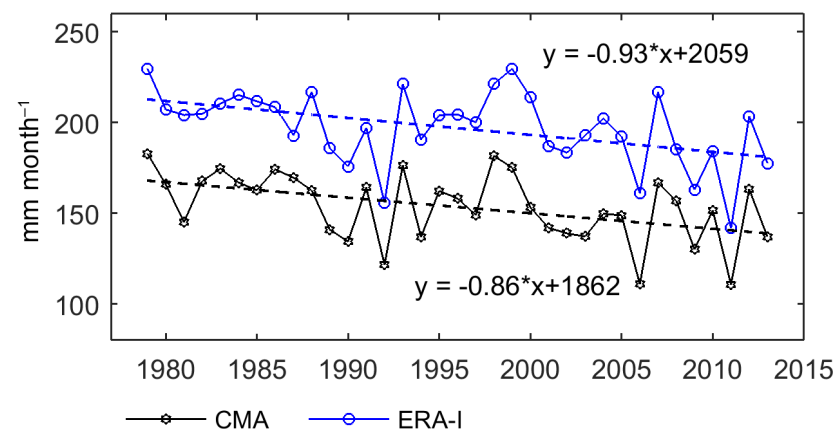

Figure 2. The time series of (a) annual and (b) July, August, and September (JAS) SWC precipitation from 1979 to 2013 with ERA-I (blue line) and CMA (black line) data. The trends are all significant at the $5 \%$ level based on the two-tailed Student's $t$ test.

sient component is the transient moisture transported by the transient eddies.

The fluctuation of the stationary component in expression of divergence can be further decomposed into thermodynamic and dynamic terms (Eq. 2; Seager et al., 2010; L. Li et al., 2013).

$\delta \underbrace{\left(\int_{P_{\mathrm{t}}}^{P_{\mathrm{s}}} \nabla \cdot(\bar{q} \overline{\boldsymbol{V}}) \mathrm{d} p\right)}_{\text {Stationary }} \approx \underbrace{\int_{P_{\mathrm{t}}}^{P_{\mathrm{s}}} \nabla \cdot\left(\bar{q}_{a} \overline{\boldsymbol{V}}_{c}\right) \mathrm{d} p}_{\text {Thermodynamic }}+\underbrace{\int_{P_{\mathrm{t}}}^{P_{\mathrm{s}}} \nabla \cdot\left(\bar{q}_{c} \overline{\boldsymbol{V}}_{a}\right) \mathrm{d} p}_{\text {Dynamic }}$,

where $\nabla \cdot$ is the divergence operator and the divergence is calculated directly from the field of moisture flux; $\delta$ denotes the fluctuation of the stationary component to its climatology; the subscript " $c$ " denotes climatology and " $a$ " the interannual deviation from the climatology; $\overline{\mathrm{q}}_{c}$ and $\overline{\boldsymbol{V}}_{c}$ are the 35-year climatology of monthly mean specific humidity and wind velocity, respectively; $\overline{\mathrm{q}}_{a}$ and $\overline{\boldsymbol{V}}_{a}$ are the deviations from the 35-year climatology of each month. The thermodynamic (dynamic) component is solely determined by the changes in specific humidity (wind velocity) and thus represents the thermodynamic (dynamic) contribution (L. Li et al., 2013).

\section{Results and discussion}

Figure 1b shows the annual precipitation trends from 1979 to 2013 calculated from the CMA gridded precipitation over the SWC region as marked out by the red box. The SWC precipitation shows a declining trend in recent decades. The area-averaged annual SWC precipitation has decreased significantly with a rate of $-2.72 \mathrm{~mm} \mathrm{yr}^{-2}$ (Fig. 2a). Table 1 provides the monthly precipitation trends during 1979-2013. It shows that the monthly trends from March to May are positive, although they are not statistically significant. The decreasing trends are the largest in the summer months of July, August, and September (JAS) with rates of $-0.5,-1.1$, and $-1.0 \mathrm{~mm}$ month ${ }^{-1} \mathrm{yr}^{-1}$, respectively. The decreasing trend is statistically significant at the $6 \%(1 \%)$ level in August (September). The total JAS precipitation decreased significantly at the $5 \%$ level with a rate of $-0.86 \mathrm{~mm} \mathrm{month}^{-1} \mathrm{yr}^{-1}$ (Fig. 2b). The precipitation series with ERA-I over SWC are also shown in Fig. 2. It is evident that ERA-I estimates have large biases which are much larger than those with CMA especially at annual scale. However, the two series both show similar decreasing patterns and comparable trend magnitudes with the CMA precipitations. As the JAS precipitation trend accounts for a major share of annual precipitation trend (94.5\% with CMA data), the analysis below will focus on the JAS months.

\subsection{Moisture origin and the trend in moisture contribution}

The climatological moisture contributions from the source grids in JAS and their trends during 1979-2013 are shown in Fig. 3. The major moisture contributing region, i.e., grids with contribution over $0.27 \mathrm{~mm} \mathrm{month}^{-1}$, are marked out (Fig. 3a), where $88.3 \%$ of JAS precipitation moisture in SWC comes from. This threshold value is chosen subjectively to delineate the areas contributing most of JAS precipitation moisture to the SWC region. Generally, the farther away from the target region, the lower intensity of moisture is contributed to the target (C. Zhang et al., 2017; Keys et al., 2012, 2014). Yet, the lapse rate of moisture contribution intensity differs in different directions. It decreases slowly to the southwest and southeast, where moisture is transported by the Asian monsoons, indicating that the monsoon regions provide considerable amount of moisture to SWC. This result is consistent with Drumond et al. (2011), who traced precipitation moisture in Yunnan Province from April to September and found two strong moisture sources of the Arabian Sea and the BOB, respectively. In contrast, the intensity decreases rapidly to the north, suggesting that little moisture originates from the north. To the west of the SWC region, the intensity of moisture contribution is low in dry lands such as the Middle East but is relatively high in wet areas such as the Caspian Sea and the Red Sea, suggesting that these water 
Table 1. The monthly precipitation trends (mm month ${ }^{-1}$ decade $\left.^{-1}\right)$ in SWC during 1979 to 2013 . The $P$ values of the trends were calculated based on the two-tailed Student's $t$ test.

\begin{tabular}{lrrrrrrrrrrrr}
\hline Month & Jan & Feb & Mar & Apr & May & Jun & Jul & Aug & Sep & Oct & Nov & Dec \\
\hline Trend & 0.2 & -1.4 & 1.3 & 0.1 & 3.7 & -1.9 & -5.0 & -10.7 & -10.0 & -1.6 & -1.4 & -0.5 \\
$P$ value & 0.79 & 0.27 & 0.41 & 0.97 & 0.28 & 0.50 & 0.32 & 0.06 & 0.01 & 0.55 & 0.49 & 0.61 \\
\hline
\end{tabular}

(a) Climatology of summer moisture contribution $\left(\mathrm{mm} \mathrm{month}^{-1}\right)$

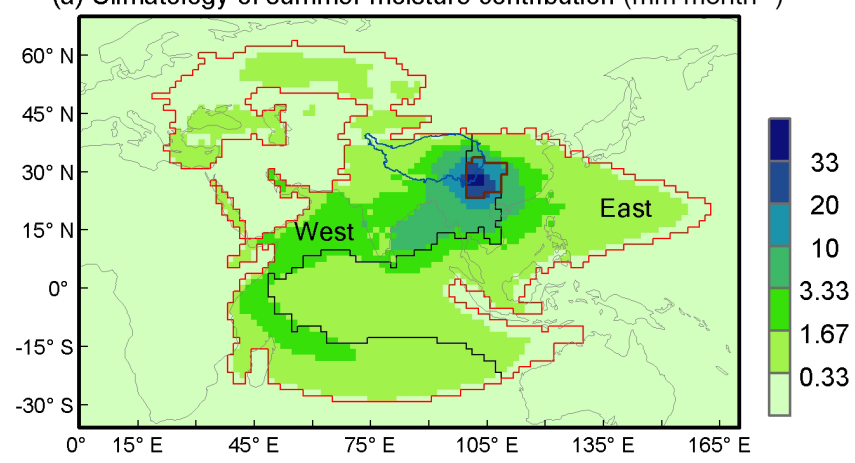

(b) The trend of JAS moisture contribution (mm month ${ }^{-1}$ decade $\left.^{-1}\right)$

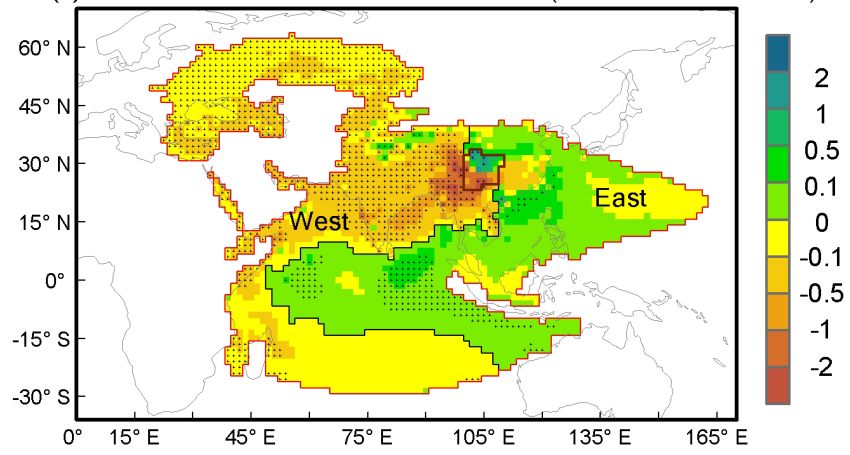

Figure 3. (a) Climatology of the July, August, and September (JAS) moisture contribution to the SWC precipitation from 1979 to 2013. The red line delineates the major source region (i.e., grids with value above $0.27 \mathrm{~mm} \mathrm{month}^{-1}$ ) which contributes $88.3 \%$ of the JAS precipitation moisture in SWC. The black line divides the major source region into the extended west, SWC, and extended east regions. The blue line delineates the Tibetan Plateau (Zhang et al., 2014). (b) The trend of the JAS moisture contribution from 1979 to 2013. The dots indicate a trend at the $5 \%$ significance level based on the $t$ test. Values outside the major region are not shown.

bodies tend to provide more moisture than the neighboring dry lands.

As the moisture contribution trends show an opposite pattern in the west and east (Fig. 3b), the major moisture contributing region is divided into three regions, namely the extended west, SWC, and the extended east regions. The extended west region covers an area west and southwest to SWC, and the extended east region covers an area east to SWC and a part of the Indian Ocean. Figure S1 in the Supplement shows the climatological moisture transport from July to September. It indicates moisture from the extended west region largely enters the western and southern borders of SWC, whereas moisture from the extended east region enters the eastern border via a route through SCS. Moisture from the extended west region is likely affected by the South Asian summer monsoon (SASM) and the westerlies, while that from the extended east region is likely affected by the East Asian summer monsoon (EASM). When summed over regions, the extended west, SWC, and the extended east regions contribute $48.2,15.5$, and $24.5 \%$ of the total precipitation moisture, respectively. As SWC situates eastward and downwind of the Tibetan Plateau (Fig. S1), moisture from regions to the west of the plateau is mainly blocked by the plateau, while the plateau itself serves as a more important moisture source. According to statistics, the Tibetan Plateau contributes around $11.5 \%$ of the SWC precipitation, less than that from the SASM and EASM regions. Huang and Cui (2015) also notified the important role of Tibetan Plateau as a major source to provide moisture for precipitation in the Sichuan Basin. As the basin situates in north SWC, south SWC is, however, more accessible to the monsoons (Drumond et al., 2011). Thus, it is reasonable that the monsoons, which bring abundant moisture, contribute primary moisture to the JAS precipitation in SWC, while the westerlies contribute secondarily.

Moisture supply (i.e., moisture contributed to the SWC precipitation) from most of the extended west region experienced a decreasing trend of $-7.9 \mathrm{~mm} \mathrm{month}^{-1}$ decade $^{-1}$, accounting for $91.7 \%$ of the SWC precipitation trend, while that from most of the extended east region experienced an increasing trend of $1.4 \mathrm{~mm} \mathrm{month}^{-1}$ decade $^{-1}$ (Fig. 3b). The trend of local moisture contribution to SWC precipitation is $-0.4 \mathrm{~mm} \mathrm{month}^{-1} \mathrm{decade}^{-1}$, accounting for $4.6 \%$ of the SWC precipitation trend, which suggests that change in local recycling played a minor role in the precipitation decrease over SWC.

Figure 4 shows the changes in moisture contribution and moisture transport in July, August, and September between the first and last 10 years of the period of 1979-2013. Overall, there is an apparent decline of moisture supply from the west and southwest regions to SWC in all the 3 months. The area with the largest decline of moisture contribution includes the Indian subcontinent and Indochina over the land and the $\mathrm{BOB}$ over the sea. Compared with the moisture transport in the first 10 years, more moisture from the Indian Ocean has been routed to the northern Indian subcontinent or the Tibetan Plateau, rather than into SWC in the last 10 

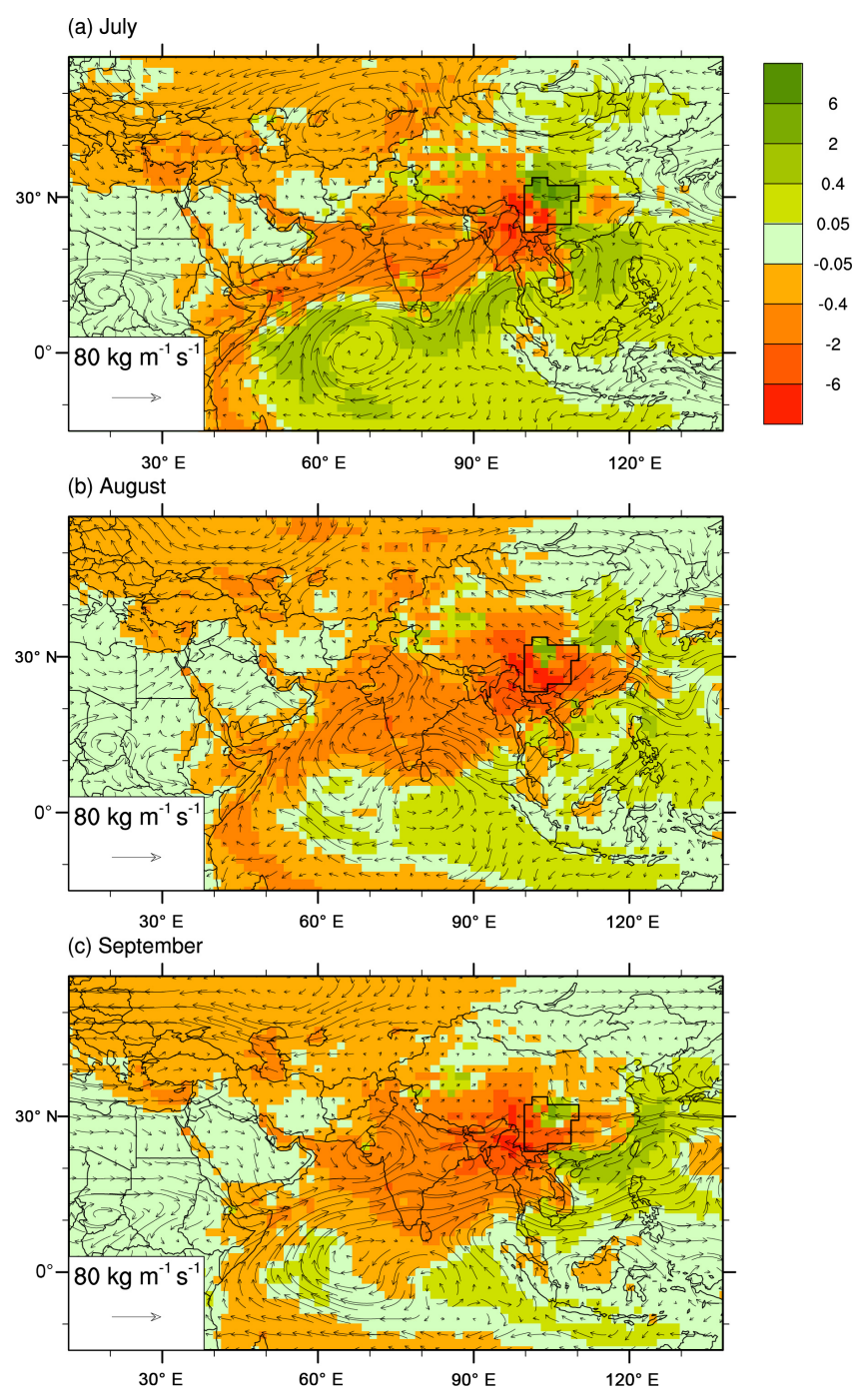

Figure 4. The difference of mean moisture contribution (unit: mm month ${ }^{-1}$; shading) in July (a), August (b), and September (c) between 2004-2013 and 1979-1988. The vectors represent the difference of moisture transport.

years. Consequently, moisture contribution influenced by the SASM is weakened. In contrast, moisture contribution has increased in many parts of the extended east region. In July, the area with increased moisture contribution includes the northern central Indian Ocean, SCS, and a northeastern area of SWC. It looks like that more moisture from the northern central Indian Ocean has been routed to SWC via SCS in the last decade of 1979-2013. In August and September, the main area with increased moisture contribution is located to the east and south of SWC, while a part of the northern central Indian Ocean also contributed more moisture to SWC compared to the first 10 years. The prevailing easterly moisture transport in recent decades in South China supports an enhanced contribution of the SWC precipitation moisture from the EASM region. The southern part of SWC that is (a) Climatology of moisture divergence in SWC

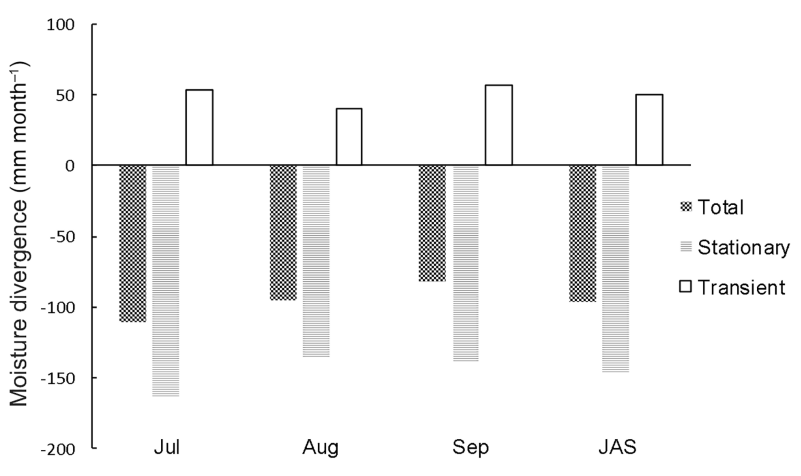

(b) Moisture divergence series in SWC

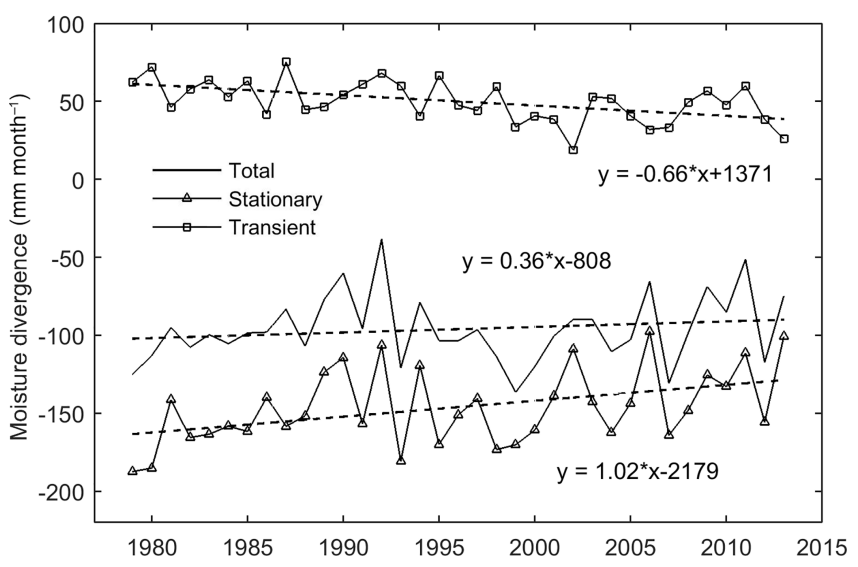

Figure 5. (a) Areal moisture divergence and its stationary and transient components over the SWC (unit: $\mathrm{mm} \mathrm{month}{ }^{-1}$ ) for July, August, and September during 1979-2013. (b) Moisture divergence in JAS and its stationary and transient components (unit: mm month ${ }^{-1}$ ) over the SWC during 1979-2013.

largely affected by the SASM and westerlies experienced a decrease in moisture contribution.

\subsection{Thermodynamic and dynamic control of moisture transport}

The role of moisture transport is further investigated by analyzing the relations between moisture divergence and precipitation over SWC during 1979-2013. Correlation coefficients between moisture divergence and precipitation over SWC are calculated, which are as $-0.87,-0.88$, and -0.74 for July, August, and September, respectively. As evaporation is another component that forms the long-term moisture balance equation of $P=E-\operatorname{div}(Q)$, the correlation coefficients between $P$ and $E$ are also calculated, which are $-0.18,0.39$, and 0.23 for July, August, and September, respectively. The much closer correlations between moisture divergence and precipitation indicate that remote moisture transport is more important than local surface evaporation in regulating the interannual variation in JAS precipitation (X. Li et al., 2013). 


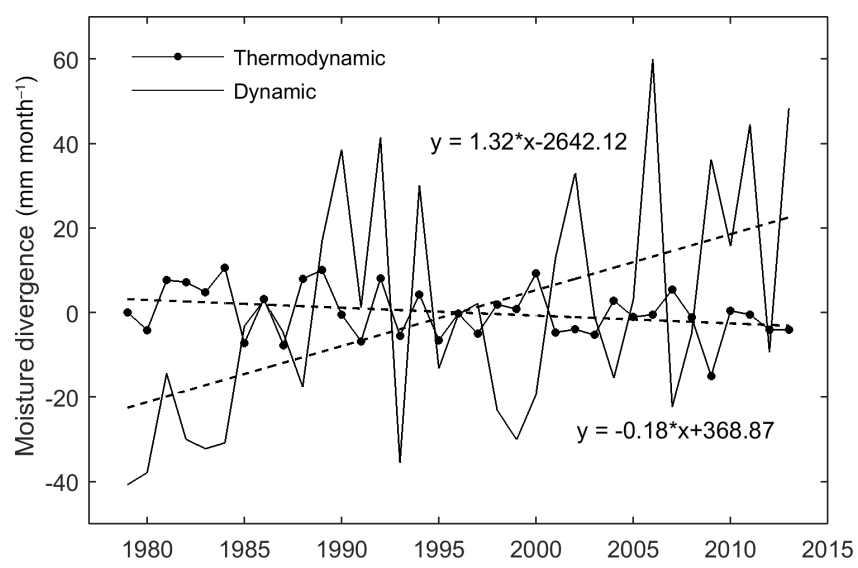

Figure 6. The anomalies of moisture divergence over JAS SWC (unit: $\mathrm{mm} \mathrm{month}^{-1}$ ) caused by thermodynamic and dynamic terms during 1979-2013.

Figure 5 shows the 35-year climatology and time series of moisture divergence over SWC and their stationary and transient parts. The moisture divergences over SWC are negative, as expected (see also Fig. S1). The stationary component of moisture divergence is also negative. The transient component is, however, positive. It indicates the transient eddies counteract the mean flow in moisture flux convergence/divergence in SWC. The magnitude of the transient component is about $30 \%$ of that of the stationary component, further suggesting that the change in the stationary component plays a major role in changing the moisture divergence over SWC (Fig. 5a). During 1979-2013, the stationary component increased and the transient component decreased, resulting in an increasing trend of the moisture divergence (Fig. 5b). This suggests that the change in the mean flow rather than the transient eddies has led to the decrease in JAS precipitation in SWC.

Figure 6 shows the changes in thermodynamic and dynamic components of the stationary moisture transport in JAS over SWC during 1979-2013. The variation in the thermodynamic component is small compared with that of the dynamic component, suggesting that the dynamic processes, i.e., changes in atmospheric circulation (wind), exerted a dominant influence on the variation in moisture transport. The dynamic component shows an increasing trend significant at 5\% level during 1979-2013, while the thermodynamic component shows a small negative trend. The increase in moisture divergence, i.e., decrease in moisture convergence, by the dynamic component is in line with the decreasing precipitation (Table 1). The correlation coefficients between the dynamic component of moisture transport and precipitation over SWC are calculated. According to the calculated coefficients of determination, the dynamic component explains 80,81 , and $58 \%$ of the precipitation variances for July, August, and September, respectively. It confirms the dominant role of the dynamic processes in regulat-
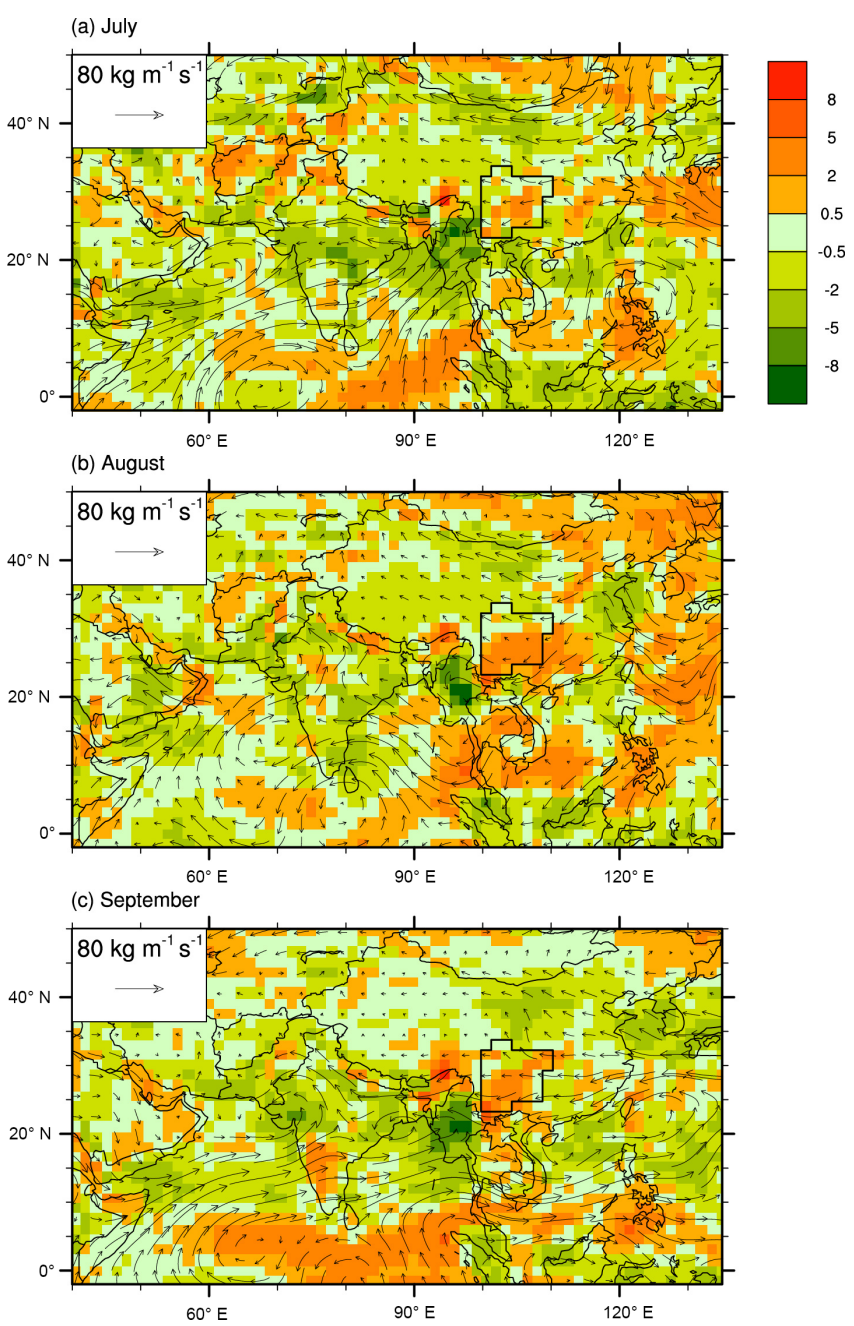

Figure 7. The monthly difference flux (vectors) of the dynamic component of the stationary moisture transport between the last and first 10 years (last-first) and its divergence (unit: $10^{-5} \mathrm{~kg} \mathrm{~m}^{-2} \mathrm{~s}^{-1}$; shading).

ing the precipitation change in SWC. Indeed, the interannual variation in the SASM net precipitation (within the Arabian Sea-Indian Subcontinent-BOB) is also dominated by the dynamic processes (Walker et al., 2015). This suggests that the dominant role played by the dynamic processes in regulating moisture transport and regional precipitation not only validates in SWC but prevails over a quite large area.

Figure 7 compares the dynamic component in JAS between the first and last 10 years of the period of 1979 2013. There is an overall positive anomaly of moisture divergence over SWC with an easterly anomaly of moisture transport. Though there is a southwesterly anomaly of moisture transport from the Indian Ocean to the SWC direction in July and September, it does not contribute moisture transport to SWC because the anomaly ends on the south of the Tibetan Plateau. There is an easterly anomaly along the southern edge of the Tibetan Plateau, routing the moisture trans- 
(a) Zonal moisture flux shear factor

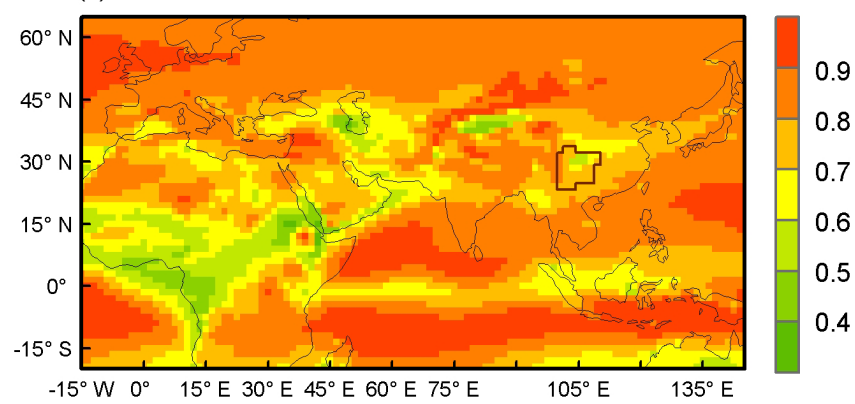

(b) Meridional moisture flux shear factor

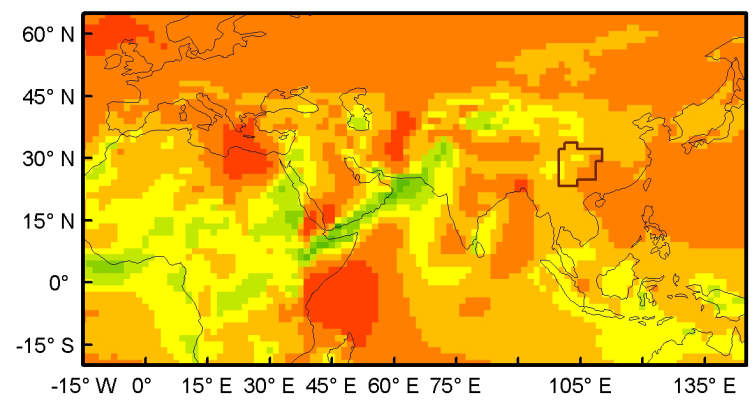

Figure 8. Horizontal moisture flux shear factor in JAS averaged over 1979-2013 with ERA-I. (a) Zonal moisture flux shear factor and (b) meridional moisture flux shear factor.

port to the northern Indian subcontinent instead of the SWC region. The anomaly of moisture divergence, dynamically caused by the changes in circulation, is generally negative in the Indian subcontinent but positive in SWC (Tan et al., 2016). The prevailing easterly anomaly of moisture transport and pronounced regional anomalies of moisture divergence over SWC are likely to result from the change in the Asian summer monsoon system (Wei et al., 2014), which might be related to recent Pacific cooling and Indian Ocean warming (Ueda et al., 2015).

\section{Sensitivity analysis}

\subsection{On WAM}

In the study, the one vertical layer version of WAM (WAM1) was applied. WAM1 uses the vertically integrated fluxes with the moisture being well-mixed within the atmospheric column. In reality, "well-mixed" conditions of tagged atmospheric moisture are usually not met (Bosilovich, 2002; Goessling and Reick, 2013). At the same time, if the horizontal winds are sheared vertically in direction, vertical inhomogeneities will generate, which may lead to substantial errors with 2-D moisture tracking models (Goessling and Reick, 2013). Van der Ent et al. (2013) advanced WAM1 to the two vertical layer WAM (WAM2) that satisfyingly solved this problem and gave a simple metric to assess wind shear on when to use which model. The equations on the horizontal

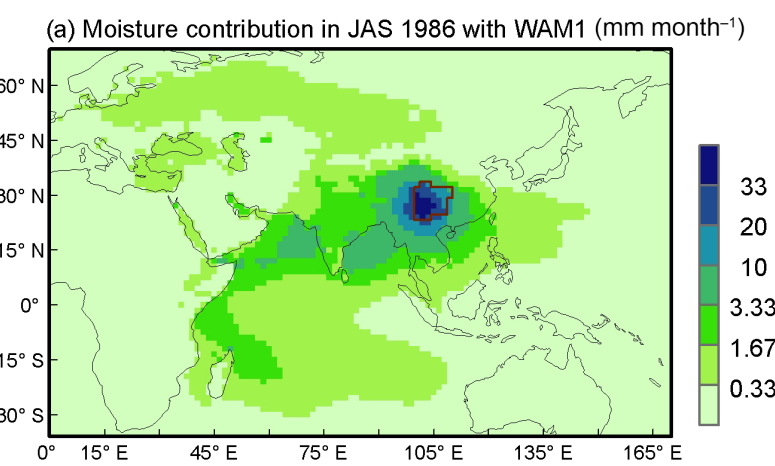

(b) Moisture contribution in JAS 1986 with WAM2 (mm month $\left.{ }^{-1}\right)$

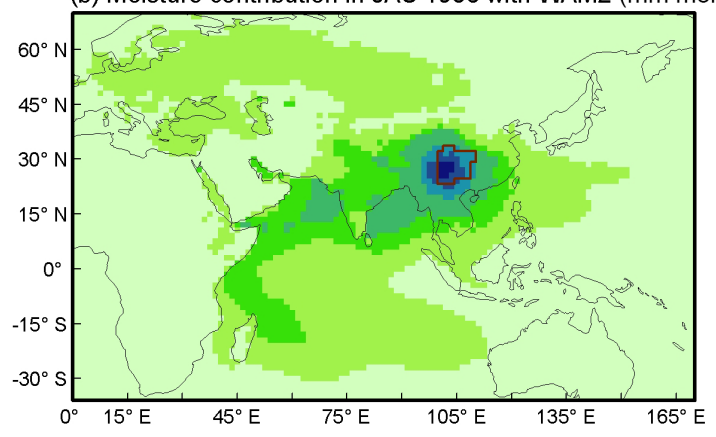

Figure 9. Moisture contribution of the SWC precipitation in JAS 1986 with WAM1 (a) and WAM2 (b).

moisture flux shear following van der Ent et al. (2013) are

$F_{\mathrm{Z}}=\frac{\left|\int_{P_{\mathrm{t}}}^{P_{\mathrm{s}}} q u \mathrm{~d} p\right|}{\int_{P_{\mathrm{t}}}^{P_{\mathrm{s}}}|\mathrm{q} u| \mathrm{d} p}$

and

$F_{\mathrm{m}}=\frac{\left|\int_{P_{\mathrm{t}}}^{P_{\mathrm{s}}} q v \mathrm{~d} p\right|}{\int_{P_{\mathrm{t}}}^{P_{\mathrm{s}}}|q v| \mathrm{d} p}$,

where $F_{\mathrm{z}}$ and $F_{\mathrm{m}}$ represent the zonal and meridional moisture flux shear, respectively. It can be easily judged that the flux shear value falls on a range between 0 and 1 . The lower the value, the stronger the moisture flux shear. The climate means of horizontal moisture flux shear factors in JAS from 1979 to 2013 are shown in Fig. 8. The areal-weighted shear factor at the zonal direction over JAS SWC during 19792013 is 0.72 , while it is 0.76 at the meridional direction. Taking the zonal shear factor as an example, a shear factor of 0.72 means that $86 \%$ of the water goes in one direction with $14 \%$ in the opposite direction. Because the dominant moisture flux has a high share of the overall flux, the moisture flux shear is rather small in this case.

To further verify the applicability of WAM1, the year 1986, with the strongest moisture flux shear (the averaged zonal and meridional shear factor in JAS 1986 is 0.71), was selected to perform an inter-model comparison between WAM1 and WAM2. As the atmospheric input data 
(a) Climatology of summer moisture contribution (mm month ${ }^{-1}$ )

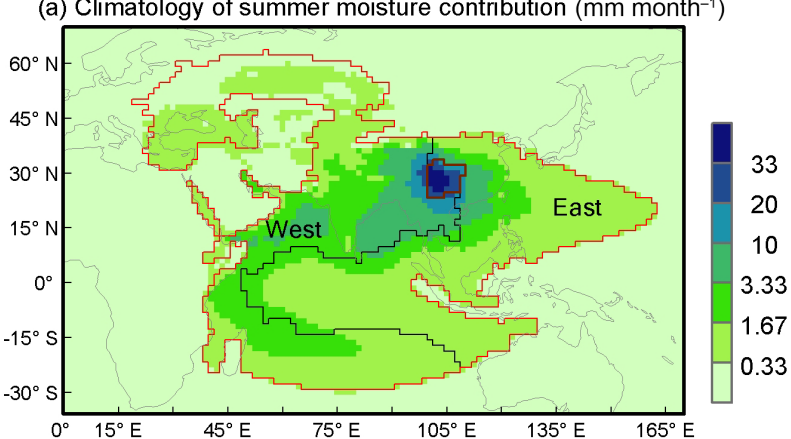

(b) The trend of JAS moisture contribution (mm month ${ }^{-1}$ decade $^{-1}$ )

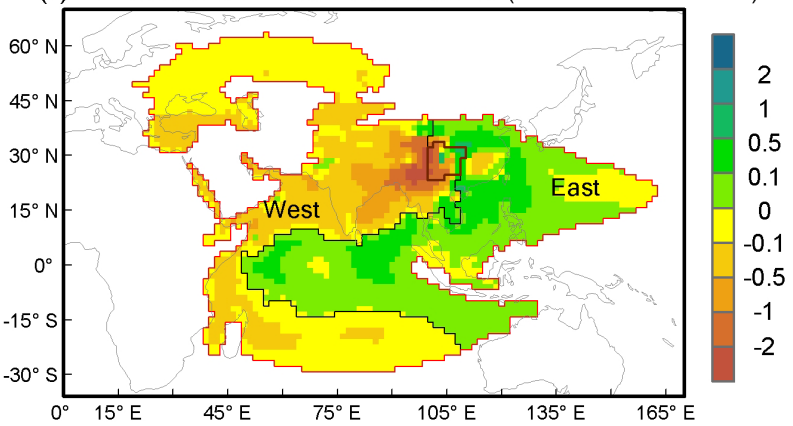

Figure 10. (a) Climatology of the JAS moisture contribution to the SWC precipitation from 1979 to 2013 with ERA-I $E$ and $P$. (b) The trend of the JAS moisture contribution from 1979 to 2013 with ERA-I $E$ and $P$. The red line and east-west division are the same as in Fig. 3.

for WAM2 are model-level based, additional suite of ERAI model-level atmospheric data in 1986 was prepared. The moisture contribution for JAS precipitation in 1986 SWC with WAM1 and WAM2 is shown in Fig. 9. It demonstrates that the spatial patterns of moisture contribution between WAM1 and WAM2 match quite well with each other.

\subsection{On ERA-I data}

ERA-I, as a modern reanalysis, has significantly improved in comparison to its prior version, ERA-40 (Dee et al., 2011; Trenberth et al., 2011). The ERA-I variables differ according to whether they are produced by the analysis or the forecast. The analysis fields are constrained by the observations while the forecast are produced by the model (Berrisford et al., 2011; Dee et al., 2011). Thus, observation-constrained fields such as humidity and wind tend to be more reliable than those from model forecast as precipitation, evaporation, etc. (Berrisford et al., 2011), as does the moisture transport derived from humidity and wind directly. In a comparison among several reanalyses (Trenberth et al., 2011), the longterm variation in moisture transport with ERA-I is rather stable, which gives us more confidence in its application.

As in the study, observation-based precipitation (from CMA) and evaporation (GLDAS, forced with precipitation gauge observations) instead of their ERA-I forecast counter- parts were used. On the one hand, the input data for WAM becomes more accurate which facilitates more accurate results. On the other hand, changes in the ERA-I water cycle may induce changes in moisture origin and may further affect the trend results. In that consideration, moisture tracking for the SWC precipitation with the original ERA-I evaporation and precipitation is also performed. The basic results are shown in Fig. 10. The basic patterns of moisture contribution with different $E$ and $P$ are similar (cf. Figs. 3a and 10a), except that sources with ERA-I $E$ and $P$ tend to contribute more moisture, since the SWC precipitation in JAS is higher with ERA-I than with CMA (see Fig. 2b). The major region (enclosed by the $0.27 \mathrm{~mm}^{\text {month }}{ }^{-1}$ red line in Fig. 3a) contributes $89.4 \%$ with ERA-I $E$ and $P$. The trend patterns are generally the same between both datasets (cf. Figs. $3 \mathrm{~b}$ and $10 \mathrm{~b})$. Though there are small differences in the magnitude of the rate and sometimes in rate signs over a few grids, the "east-increase, west-decrease" pattern remains unchanged. Thus, the major conclusions based on results with changed $E$ and $P$ remain unchanged. Instead, the application of CMA and GLDAS data tend to provide more reliable estimations. The small influence of evaporation and precipitation highlights the importance of moisture transport. It is mainly due to the change in moisture transport that redistributes moisture and leads to changes in moisture contributed to SWC as well as precipitation there.

\section{Conclusions}

JAS precipitation over SWC has decreased significantly during 1979-2013. By tracing the origins of moisture for JAS precipitation and by analyzing the variations in moisture transport to SWC, we came to the following conclusions.

1. Most moisture for the JAS precipitation in SWC originates in regions from the northern Indian Ocean to SWC and from South China Sea to SWC. The westerlies play a secondary role in supplying moisture. The extended west region, SWC, and the extended east region contributes $48.2,15.5$, and $24.5 \%$ of moisture to the JAS precipitation in SWC, respectively. The Tibetan Plateau region contributes $11.5 \%$ of the moisture for precipitation.

2. The decrease in the JAS precipitation is mainly attributed to the reduced moisture supply from the extended west region. Moisture supply from the extended west region has decreased at a high rate $\left(-7.9 \mathrm{~mm} \mathrm{month}^{-1} \mathrm{decade}^{-1}\right)$, and that from the extended east has increased at a low rate $\left(1.4 \mathrm{~mm} \mathrm{month}^{-1} \mathrm{decade}^{-1}\right)$, resulting in an overall decrease in the moisture supply.

3. The change in the stationary component has reduced moisture transport into SWC in JAS, whereas the 
change in transient component has increased moisture transport during 1979-2013. The dynamic processes (i.e., changes in wind) are more important than the thermodynamic processes (i.e., changes in specific humidity) in affecting the precipitation. A prevailing easterly anomaly that weakened moisture transport from the Indian Ocean is mainly responsible for the decrease in the SWC precipitation. The change in circulation may be related to the recent sea surface temperature change and need further investigation.

Data availability. The ERA-I data are supplied by ECMWF and are accessible at http://apps.ecmwf.int/datasets/data/ interim-full-daily/. The GLDAS data are supplied by the NASA Goddard Earth Sciences Data and Information Services Center (GES DISC) and are accessible at https://ldas.gsfc.nasa.gov/gldas/. The CMA precipitation dataset is provided by China Meteorological Data Service Center (CMDC) and is accessible at http://data.cma.cn/en. The GLOBE elevation data are downloaded from https://www.ngdc.noaa.gov/mgg/topo/globe.html.

\section{The Supplement related to this article is available online at https://doi.org/10.5194/acp-17-10383-2017- supplement.}

Competing interests. The authors declare that they have no conflict of interest.

Acknowledgements. This work was supported through the National Natural Science Foundation of China (41425002), the Key Research Program of the Chinese Academy of Sciences (ZDRW-ZS-2016-6-4), and the National Youth Top-notch Talent Support Program in China. Support from Swedish VR, STINT, BECC, MERGE and SNIC through S-CMIP is also acknowledged.

Edited by: Andreas Stohl

Reviewed by: two anonymous referees

\section{References}

Barriopedro, D., Gouveia, C. M., Trigo, R. M., and Wang, L.: The 2009/10 drought in China: possible causes and impacts on vegetation, J. Hydrometeor., 13, 1251-1267, 2012.

Berrisford, P., Kållberg, P., Kobayashi, S., Dee, D., Uppala, S., Simmons, A. J., Poli, P., and Sato, H.: Atmospheric conservation properties in ERA-Interim, Q. J. Roy. Meteor. Soc., 137, 13811399, https://doi.org/10.1002/qj.864, 2011.

Bosilovich, M. G.: On the vertical distribution of local and remote sources of water for precipitation, Meteorol. Atmos. Phys., 80, 31-41, https://doi.org/10.1007/s007030200012, 2002.

Dee, D. P., Uppala, S. M., Simmons, A. J., Berrisford, P., Poli, P., Kobayashi, S., Andrae, U., Balmaseda, M. A., Balsamo, G.,
Bauer, P., Bechtold, P., Beljaars, A. C. M., van de Berg, L., Bidlot, J., Bormann, N., Delsol, C., Dragani, R., Fuentes, M., Geer, A. J., Haimberger, L., Healy, S. B., Hersbach, H., Hólm, E. V., Isaksen, L., Kållberg, P., Köhler, M., Matricardi, M., McNally, A. P., Monge-Sanz, B. M., Morcrette, J.-J., Park, B.-K., Peubey, C., de Rosnay, P., Tavolato, C., Thépaut, J.-N., and Vitart, F.: The ERA-Interim reanalysis: Configuration and performance of the data assimilation system, Q. J. Roy. Meteor. Soc., 137, 553-597, https://doi.org/10.1002/qj.828, 2011.

Draxler, R. R. and Hess, G. D.: Description of the HYSPLIT_4 modeling system of trajectories, dispersion, and deposition, Austral. Meteorol. Mag., 47, 295-308, 1998.

Drumond, A., Nieto, R., and Gimeno, L.: Sources of moisture for China and their variations during drier and wetter conditions in 2000-2004: A Lagrangian approach, Clim. Res., 50, 215-225, https://doi.org/10.3354/cr01043, 2011.

Feng, L., Li, T., and Yu, W.: Cause of severe droughts in Southwest China during 1951-2010, Clim. Dynam., 43, 2033-2042, 2014.

Gao, Y., Lan, C., and Zhang, Y.: Changes in moisture flux over the Tibetan Plateau during 1979-2011 and possible mechanisms, J. Clim., 27, 1876-1893, https://doi.org/10.1175/JCLI-D13-00321.1, 2014

Goessling, H. F. and Reick, C. H.: On the "well-mixed" assumption and numerical 2-D tracing of atmospheric moisture, Atmos. Chem. Phys., 13, 5567-5585, https://doi.org/10.5194/acp13-5567-2013, 2013.

Gustafsson, M., Rayner, D., and Chen D.: Extreme rainfall events in southern Sweden: where does the moisture come from?, Tellus A, 62, 605-616, https://doi.org/10.1111/j.16000870.2010.00456.x, 2010.

He, J., Yang, X., Li, Z., Zhang, X., and Tang, Q.: Spatiotemporal variations of meteorological droughts in China during 1961-2014: An investigation based on multi-threshold identification, International Journal of Disaster Risk Science, 7, 63-76, https://doi.org/10.1007/s13753-016-0083-8, 2016.

Huang, Y. and Cui, X.: Moisture sources of torrential rainfall events in the Sichuan Basin of China during summers of 2009-13, J. Hydrometeor., 16, 1906-1917, https://doi.org/10.1175/JHM-D14-0220.1, 2015.

James, P., Stohl, A., Spichtinger, N., Eckhardt, S., and Forster, C.: Climatological aspects of the extreme European rainfall of $\mathrm{Au}-$ gust 2002 and a trajectory method for estimating the associated evaporative source regions, Nat. Hazards Earth Syst. Sci., 4, 733746, https://doi.org/10.5194/nhess-4-733-2004, 2004.

Keys, P. W., van der Ent, R. J., Gordon, L. J., Hoff, H., Nikoli, R., and Savenije, H. H. G.: Analyzing precipitation sheds to understand the vulnerability of rainfall dependent regions, Biogeosciences, 9, 733-746, https://doi.org/10.5194/bg-9-7332012, 2012.

Keys, P. W., Barnes, E. A., van der Ent, R. J., and Gordon, L. J.: Variability of moisture recycling using a precipitationshed framework, Hydrol. Earth Syst. Sci., 18, 3937-3950, https://doi.org/10.5194/hess-18-3937-2014, 2014.

Li, L., Li, W., and Barros, A. P.: Atmospheric moisture budget and its regulation of the summer precipitation variability over the Southeastern United States, Clim. Dynam., 41, 613-631, 2013.

Li, X., Zhou, W., Li, C., and Song, J.: Comparison of the annual cycles of moisture supply over southwest and southeast China, J. Clim., 26, 10139-10158, 2013. 
Li, Y., Xu, H., and Liu, D.: Features of the extremely severe drought in the east of Southwest China and anomalies of atmospheric circulation in summer 2006, J. Meteor. Res., 25, 176-187, 2011.

Liu, X., Yang, Q., and Cheng, B.: Study on anomalies of atmospheric circulation and water vapor field of the heavy drought in Sichuan-Chongqing region in midsummer 2006 (in Chinese), Meteor. Mon., 35, 27-34, 2009.

Lu, E., Luo, Y., Zhang, R., Wu, Q., and Liu L.: Regional atmospheric anomalies responsible for the 2009-2010 severe drought in China, J. Geophys. Res., 116, D21114, https://doi.org/10.1029/2011JD015706, 2011.

Numaguti, A.: Origin and recycling processes of precipitating water over the Eurasian continent: Experiments using an atmospheric general circulation model, J. Geophys. Res., 104, 1957-1972, https://doi.org/10.1029/1998jd200026, 1999.

Rodell, M., Houser, P., Jambor, U., Gottschalck, J., Mitchell, K., Meng, C., Arsenault, K., Cosgrove, B., Radakovich, J., Bosilovich, M., Entin, J., Walker, J., Lohmann, D., and Toll D.: The global land data assimilation system, Bull. Amer. Meteor. Soc., 85, 381-394, 2004.

Seager, R., Naik, N., and Vecchi, G. A.: Thermodynamic and dynamic mechanisms for large-scale changes in the hydrological cycle in response to global warming, J. Clim., 23, 4651-4668, 2010.

Shen, Y. and Xiong, A.: Validation and comparison of a new gaugebased precipitation analysis over mainland China, Int. J. Climatol., 36, 252-265, 2016.

Sodemann, H. and Zubler, E.: Seasonal and inter-annual variability of the moisture sources for Alpine precipitation during 19952002, Int. J. Climatol., 30, 947-961, 2010.

Sodemann, H., Schwierz, C., and Wernli, H.: Interannual variability of Greenland winter precipitation sources: Lagrangian moisture diagnostic and North Atlantic Oscillation influence, J. Geophys. Res., 113, D03107, https://doi.org/10.1029/2007JD008503, 2008.

Stohl, A. and James, P.: A Lagrangian analysis of the atmospheric branch of the global water cycle, Part I: Method description, validation, and demonstration for the August 2002 flooding in Central Europe, J. Hydrometeorol., 5, 656-678, 2004.

Stohl, A. and James, P.: A Lagrangian analysis of the atmospheric branch of the global water cycle, Part II: Moisture transports between Earth's ocean basins and river catchments, J. Hydrometeorol., 6, 961-984, 2005.

Tan, L., Cai, Y., An, Z., Cheng, H., Shen, C., Gao, Y., and Edwards, R. L.: Decreasing monsoon precipitation in southwest China during the last 240 years associated with the warming of tropical ocean, Clim. Dynam., 48, 1769-1778, 2016.

Tong, K., Su, F., Yang, D., Zhang, L., and Hao, Z.: Tibetan Plateau precipitation as depicted by gauge observations, reanalyses and satellite retrievals, Int. J. Climatol., 34, 265-285, 2014.

Trenberth, K. E.: Atmospheric moisture residence times and cycling: Implications for rainfall rates and climate change, Climatic Change, 39, 667-694, https://doi.org/10.1023/A:1005319109110, 1998.

Trenberth, K. E.: Atmospheric moisture recycling: Role of advection and local evaporation, J. Clim., 12, 1368-1381, 1999.

Trenberth, K. E., Fasullo J. T., and Mackaro J.: Atmospheric moisture transports from ocean to land and global energy flows in reanalyses, J. Clim., 24, 4907-4924, 2011.
Ueda, H., Kamae, Y., Hayasaki, M., Kitoh, A., Watanabe, S., Miki, Y., and Kumai, A.: Combined effects of recent Pacific cooling and Indian Ocean warming on the Asian monsoon, Nat. Commun., 6, 8854, https://doi.org/10.1038/ncomms9854, 2015.

van der Ent, R. J., and Savenije, H. H. G.: Length and time scales of atmospheric moisture recycling, Atmos. Chem. Phys., 11, 18531863, https://doi.org/10.5194/acp-11-1853-2011, 2011.

van der Ent, R. J., Savenije, H. H. G., Schaefli, B., and Steele-Dunne, S. C.: Origin and fate of atmospheric moisture over continents, Water Resour. Res., 46, W09525, https://doi.org/10.1029/2010WR009127, 2010.

van der Ent, R. J., Tuinenburg, O. A., Knoche, H. R., Kunstmann, H., and Savenije, H. H. G.: Should we use a simple or complex model for moisture recycling and atmospheric moisture tracking?, Hydrol. Earth Syst. Sci., 17, 4869-4884, https://doi.org/10.5194/hess-17-4869-2013, 2013.

Walker J. M., Bordoni, S., and Schneider, T.: Interannual variability in the large-scale dynamics of the South Asian summer monsoon, J. Clim., 28, 3731-3750, 2015.

Wang, A. and Zeng, X.: Evaluation of multi-reanalysis products with in situ observations over the Tibetan Plateau, J. Geophys. Res., 117, D05102, https://doi.org/10.1029/2011JD016553, 2012.

Wang, L., Chen, W., Zhou, W., and Huang, G.: Teleconnected influence of tropical Northwest Pacific sea surface temperature on interannual variability of autumn precipitation in Southwest China, Clim. Dynam., 45, 2527-2539, 2015 a.

Wang, L., Chen, W., Zhou, W., and Huang, G.: Drought in Southwest China: A review, Atmos. Ocean. Sci. Lett., 8, 339-344, 2015b.

Wei, W., Zhang, R., Wen, M., Rong, X., and Li, T.: Impact of Indian summer monsoon on the South Asian High and its influence on summer rainfall over China, Clim. Dynam., 43, 1257-1269, 2014.

Yang, J., Gong, D., Wang, W., Miao, H., and Mao, R.: Extreme drought event of 2009/2010 over southwestern China, Meteorol. Atmos. Phys., 115, 173-184, 2012.

Zhang, C., Tang, Q., and Chen, D.: Recent changes in the moisture source of precipitation over the Tibetan Plateau, J. Clim. 30, 1807-1819, https://doi.org/10.1175/JCLI-D-15-0842.1, 2017.

Zhang, X., Tang, Q., Liu, X., Leng, G., and Li, Z.: Soil moisture drought monitoring and forecasting using satellite and climate model data over Southwest China, J. Hydrometeor., 18, 5-23, https://doi.org/10.1175/JHM-D-16-0045.1, 2017.

Zhang, Y., Li, B., and Zheng, D.: Datasets of the boundary and area of the Tibetan Plateau, Glob. Change Res. Data Publ. Repository, https://doi.org/10.3974/geodb.2014.01.12.V1, 2014.

Zhao, Y. and Zhu, J.: Assessing quality of grid daily precipitation datasets in China in recent 50 years (in Chinese), Plateau Meteor., 24, 837-845, 2015.

Zhao, Y., Zhu, J., and Xu, Y.: Establishment and assessment of the grid precipitation datasets in China for recent 50 years (in Chinese), J. Meteor. Sci., 34, 414-420, https://doi.org/10.3969/2013jms.0008, 2014.

Zou, X. and Gao, H.: Analysis of severe drought and heat wave over the Sichuan basin in the summer of 2006 (in Chinese), Adv. Clim. Change Res., 3, 149-153, 2007. 